\title{
Tectonic vs. shallow origin of geodetically inferred ground movements: an NE Ardenne (Belgium) case
}

\author{
Alain Demoulin ${ }^{\mathrm{a}, *}$, Bernard Vliegen ${ }^{\mathrm{b}}$, Robert Charlier ${ }^{\mathrm{b}}$ \\ a Research Associate NFSR, Departement of Physical Geography and Quaternary, Université Liège, Sart Tilman, \\ Bât. B11, 4000 Liège, Belgium \\ b Departement MSM, Université Liège, quai Banning, 6, Bât. C2, 4000 Liège, Belgium
}

Received 3 February 2000; received in revised form 10 June 2000; accepted 19 June 2000

\begin{abstract}
In order to get a better insight into the temporal pattern of height change variations in a moderately seismic intraplate area, a $1 \mathrm{~km}$ long section has been weekly leveled from April, 21, 1997 to January, 12, 1998 in NE Ardenne (Belgium). As this section is located very close to a small reservoir of $25 \times 10^{6} \mathrm{~m}^{3}$, it also allowed the influence of lake level variations on the nearby ground motion to be studied. The measured height difference variations show a maximum amplitude of $3.45 \mathrm{~mm}$, with weekly values not exceeding $1 \mathrm{~mm}$. A two-dimensional (2D) finite element modeling confirms that waterload variations in the lake are the primary cause of movement of the section, inducing maximum ground subsidence of about $2 \mathrm{~cm}$ and seasonal tilting of 3-4 $\mu$ rads within a range of 2-3 km. We also show that a fault passively alters the spatial distribution of the waterload-dependent movements. The removal of this component from the observed ground motion leaves oscillating residual displacements characterized by an amplitude of $1-1.5 \mathrm{~mm}$ and a 'period' of about 2 months. We demonstrate that these displacements are independent of rainfall and probably of groundwater fluctuation too. Although most of the residual motions take place on the fault straddled by the leveling section, no credible mechanism can be found to ascribe these motions to a tectonic process. (C) 2000 Elsevier Science B.V. All rights reserved.
\end{abstract}

Keywords: Holocene; crustal; movement; leveling; loading; Western Europe

\section{Introduction}

It is widely accepted that geodetically inferred rates of vertical crustal motion in intraplate settings are mostly inconsistent with geological rates. Indeed, they are generally one order of magnitude higher than the latter [1] and moreover show in

\footnotetext{
* Corresponding author. Tel.: +32-4-366 5660; Fax: +32-4-366 5722; E-mail: ademoulin@ulg.ac.be
}

some cases sense reversals which hitherto remain poorly explained (e.g. [2-6]). Many authors have thus interpreted these present-day ground movements as a noise of atmospheric or hydrological origin [7], also partly related to the instability of the geodetic monuments [8] and interfering with possible tectonic displacements. Although most ground tilting studies record very local deformation, they also confirm the prominent influence of the hydrological factor especially on short-term motions [9-12]. However, this opinion rather complicates the understanding of the local move- 
ments inferred from leveling comparison since it implies that only the highest of them would be tectonically significant, therefore increasing the discrepancy between long-term and short-term rate estimates. It seems highly improbable that in so many intraplate areas with limited Quaternary uplift rates, geodetic data only record 'paroxystic' tectonic movements which, in spite of their rapidity, appear unrelated to seismic activity. Furthermore, most geodetically inferred motions are tied to existing geological structures and do not show any clear relation with near-surface phenomena. Following a recent paper by Demoulin and Collignon [6] who dealt with yearly high precision levelings spanning a 5-yr period in NE Ardenne, we thus discuss here the respective influence of near-surface factors and deeper-seated causes on weekly measurements of vertical ground movements along a $1 \mathrm{~km}$ long section in the same area.

The Ardenne is a Paleozoic massif whose recent tectonic activity is weak to moderate. This activity principally appears in the NE part of the massif where it is manifested by a strong regional uplift (amounting to about $500 \mathrm{~m}$ since the Oligocene, from which $150 \mathrm{~m}$ during the Quaternary) and superimposed fault displacements. The latter take place on NNW-striking normal faults (often showing an additional strike-slip component) parallel to the major bounding faults of the nearby Rur graben. Indeed, the subsidence of the Rur graben, which belongs to the northern segment of the W-European Cenozoic rift, determines uplift mode and timing in NE Ardenne since the upper Oligocene.

Comparison of the high precision levelings carried out by the Belgian IGN (Institut Géographique National) in 1946-48 and 1972-80 demonstrates significant vertical motion located on several of the NNW-striking faults of NE Ardenne [13]. Moreover, instrumental and historical seismicities (e.g. the 1692 Verviers earthquake whose moment magnitude is estimated between 6.3 and 6.5, Camelbeeck, oral communication) characterize at least one of these faults. This is the reason why a local leveling network comprised of two loops and totaling $48 \mathrm{~km}$ was set up in the Gileppe Lake area where it runs in several places across one of the main active fault zones (Fig. 1).
Yearly reiterated surveys of this network revealed very high height change variations from one year to the other in the 1993-1998 time interval [6]. Tilt values of $0.9-1.2 \mu \mathrm{rad} / \mathrm{yr}$ have been recorded for $10 \mathrm{~km}$ long segments of the leveling route. Smaller segments (4-5 km in length and containing 6-7 regularly spaced benchmarks) even showed yearly tilting between 1.2-2.0 $\mu \mathrm{rad}$. Discrete motion was also observed at least for two NNW-striking faults. These fault displacements amount to $3-16 \mathrm{~mm}$ between two successive surveys but the cumulative movement remains limited due to frequent sense reversals.

The absence of significant systematic errors in the levelings, the nature of the local geology and especially of the surface deposits, the good quality of the geodetic monuments and the distribution of the recorded motions all converge on ruling out a shallow cause for most displacements and thus strongly suggest a tectonic origin [6]. However, several important questions are not yet solved regarding their temporal pattern. Firstly, the sense reversals which frequently characterize the motion, with an apparent periodicity of $2-3 \mathrm{yr}$, deserve more detailed investigation. Indeed, they are probably the main cause of the general inconsistency between geodetic and geologic movement rates in intraplate settings [1]. Secondly, if we wish to understand the true nature of the observed phenomenon, even a yearly frequency of survey repeating does not provide sufficient insight into the rate of displacement. Since we observe sense reversals within a few years, the movement is clearly not uniform at this timescale. However, we have no idea of its evolution between two surveys. Is it uniform through the year? Does it result from numerous uninterrupted up-and-down displacements (which themselves could be periodic - daily, seasonal - or random) or is it caused by short episodic motions briefly perturbing an otherwise still structure?

In order to answer this last question, we have carried out weekly levelings of a section of the Gileppe Lake network. 37 measurements have been performed from April 21, 1997 to January 12,1998 . The measured section, limited by benchmarks 10 and 26, is located at Béthane in the downstream part of the small Gileppe valley 


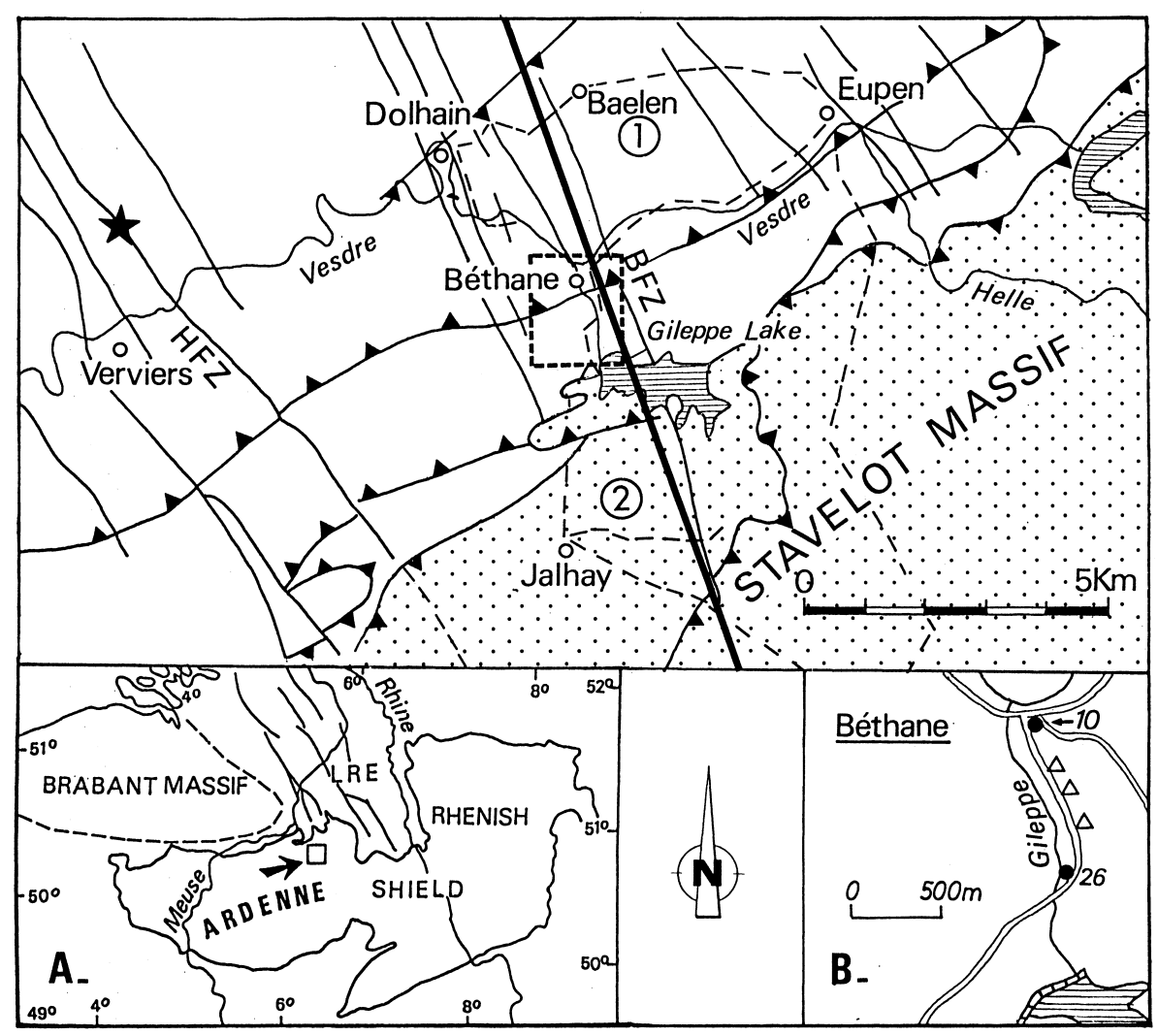

Fig. 1. Location map. Top: The Gileppe leveling network is in dashed line. The Béthane section is located at the western intersection of both leveling loops (marked by encircled numbers). The modeled cross-section is denoted by a bold line. Solid lines are for normal and thrust (with solid triangles) faults in the Paleozoic basement. HFZ, Hockai fault zone. BFZ, Baelen fault zone. The star indicates the approximate location of the historical Verviers, 1692 earthquake $\left(M_{\mathrm{w}}>6\right)$. Inset A: LRE, lower Rhine Embayment. Inset B: Black circles numbered 10 and 26 correspond to the endmarks of the Béthane section. Open triangles are for intermediate benchmarks anchored in the Paleozoic rocks.

(Fig. 1). This choice was dictated by a double purpose. On one hand, it was one of the sections which had regularly shown significant yearly vertical displacements in the 1993-1998 time interval [6]. On the other hand, it lies in a radial position at about $1 \mathrm{~km}$ to the north of the Gileppe reservoir and thus provides an opportunity for estimating the influence of load variations in the lake on ground movements.

\section{Database}

The Béthane section is $923 \mathrm{~m}$ long with a height difference of $10.74 \mathrm{~m}$ between both benchmarks, corresponding to a slope of $11.6 \%$. Beyond the endmarks, which the Belgian IGN set up in wellfounded brick buildings more than $50 \mathrm{yr}$ ago [14], it was equipped with three new benchmarks anchored in the Paleozoic bedrock at regular distances and additional topographic nails put in the asphalt road every $50 \mathrm{~m}$, so that the sight length never exceeded $25 \mathrm{~m}$. The measurements were performed using a LEICA NA-3000 numerical level and $3 \mathrm{~m}$ long code-bar invar rods. The sections have been double run with a field tolerance $\beta=1$ $\mathrm{mm} / \sqrt{ } \mathrm{km}$. During each releveling, the same rod was put on the same nails. At the end of the back run, the fore and back readings were compared for every internail distance, a discrepancy in 
excess of $0.2 \mathrm{~mm}$ compelling the remeasurement of the concerned internail distance. Air temperature readings were taken every $30 \mathrm{~min}$.

\subsection{Leveling errors}

Owing to this careful procedure, the standard error of the whole data set is only $0.19 \mathrm{~mm} / \mathrm{/} \mathrm{km}$. However, systematic errors can contaminate the levelings, and an error analysis is thus necessary.

The most significant systematic errors are generally height-dependent, closure-independent errors related to rod miscalibration and unequal atmospheric refraction effects [15,16]. The unequal refraction error arises from the vertical stratification of the air mass traversed by the sight line when leveling along inclined ground. However, the Béthane section is almost horizontal. Moreover, we always kept the sight length (which is the most influential factor) under $25 \mathrm{~m}$ and never sighted to the bottom $50 \mathrm{~cm}$ of the rods ( $92 \%$ of the readings are made between 0.9 and $2.1 \mathrm{~m})$. With regard to rod miscalibration problems, we always used the same rods on the same nails and the level station points were also the same for each successive survey. These precautions are thought to have rendered differential refraction and rod miscalibration errors negligible.

Although regularly reassessed level collimation error is automatically taken into account by the NA-3000 level, we observed equal foresight and backsight lengths (to $\pm 0.1 \mathrm{~m}$ ), which also cancels this error. The thermal error, due to thermal expansion of the invar tapes (coefficient of linear expansion $\lambda=0.8 \mathrm{ppm} /{ }^{\circ} \mathrm{C}$ ), was also corrected. The error linked to earth tides and their derived gravitational effects was not computed. Combining the effect of the tidal variations of gravity on an assumed rigid Earth with the response of the real deformable Earth to tidal stresses, the maximum possible range of lunisolar tidal influence on leveled height differences is $\sim 0.08 \mathrm{~mm} / \mathrm{km}$ [17]. Finally, a possible instrument-related error linked to differences in rod illumination may also be ruled out. Indeed, for several relevelings carried out during sunny days, no significant misclosure value arose from the fact that the fore run

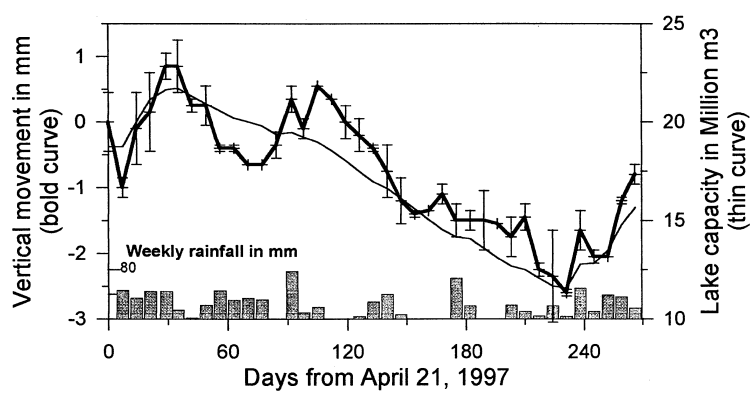

Fig. 2. Differential vertical movement recorded by weekly measurements of the Béthane section from April 21, 1997 to January 12, 1998 and its relation to rainfall and level variations of the Gileppe Lake. Vertical bars give the weekly values of section misclosure.

was performed in the morning shadow and the back run under bright sun.

Therefore, in summary, not only could any systematic error be detected but also the exact reproduction of the working conditions from one week to the other makes the differential influence of a possible undetected systematic error tend to zero.

The curve in bold of Fig. 2 shows the time dependence of the vertical position of benchmark 10 - the endmark to the north of the section, i.e. the most distant from the lake - with respect to that of benchmark 26 at the other end. The measured height difference variations between benchmarks 10 and 26 show a maximum amplitude of 3.45 $\mathrm{mm}$. Weekly values do not exceed $1 \mathrm{~mm}$. However, most of them are not only higher than the standard error but they also combine within obvious trends extending over a few months and no significant tilt excursion is found. The temperature-corrected values do not exhibit any direct relationship between ground movement and rainfall. Unfortunately, no groundwater data were available but the similar geomorphic setting of both benchmarks at barely $1 \mathrm{~km}$ from each other makes it improbable that differential variations in groundwater level be large enough to cause a tilting of the ground surface [9]. Moreover, the vertical motion of the 'intrasection' benchmarks anchored in the outcropping Paleozoic basement perfectly fits that of the endmarks 10 and 26, therefore evidencing that possible groundwater fluctuation within the alluvial deposits on which 
the endmark-bearing buildings rest does not influence the latter's stability. On the contrary, the temporal pattern of tilt variations of the Béthane section displays a striking parallelism with the curve of waterload variations within the Gileppe Lake, this small reservoir of $25 \times 10^{6} \mathrm{~m}^{3}$ maximum capacity.

\section{2D finite element modeling of the effect of waterload variations on ground movement}

In order to determine the area of influence of the varying lake level on the vertical movement of the nearby ground surface and to remove this influence from the recorded motion, we modeled the effect of such load variations by a $2 \mathrm{D}$ finite element analysis of the resulting upper crustal flexure. The modeled cross-section, which includes the leveled Béthane section, is centered on the Gileppe Lake and strikes NNW, almost perpendicularly to the lake long axis. Along this crosssection, we considered a rectangular elastic domain $20 \mathrm{~km}$ long and $15 \mathrm{~km}$ deep, the upper limit of which includes the topography (Fig. 3). The mesh density is high in the upper $3 \mathrm{~km}$ of the central part of the domain, with an average internode distance of about $100 \mathrm{~m}$ at the surface. The side areas of the domain are wider-meshed, more

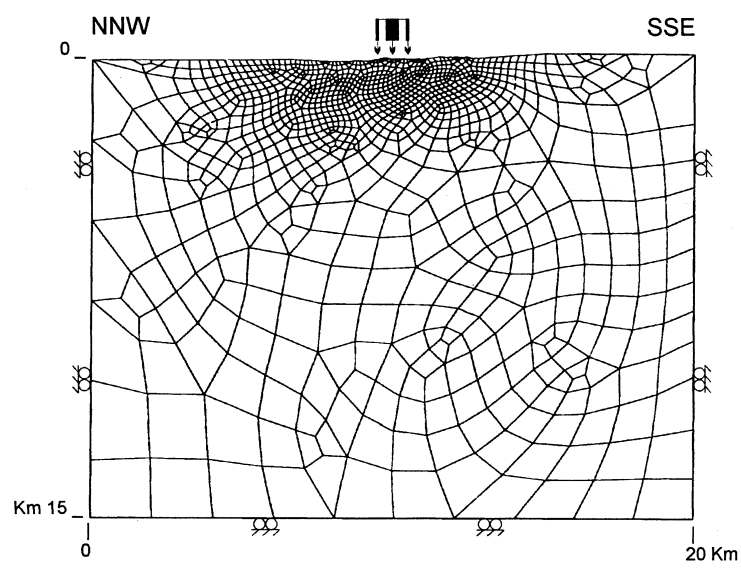

Fig. 3. Schematic diagram of the node distribution in the modeled section. The arrowing solid rectangles above the topography locate the areas where the pressure is applied.

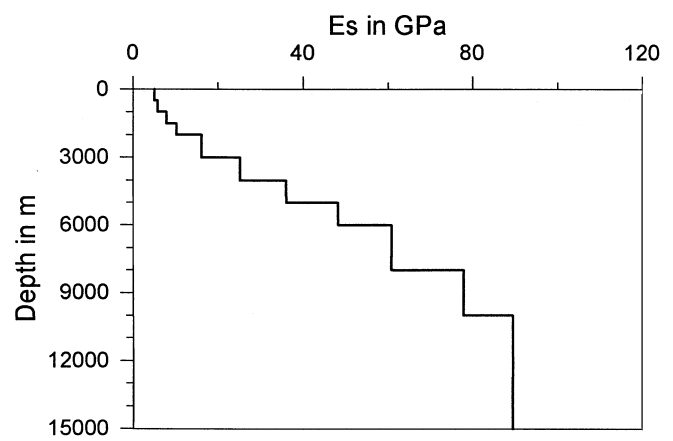

Fig. 4. Vertical profile of static modulus of elasticity computed from shear wave velocity data.

especially as the latter has been defined large enough with respect to the expected size of the deformed zone in order to avoid artificial boundary effects. The load was applied as an uniform pressure on a $551 \mathrm{~m}$ wide area corresponding to the intercepted lake surface (divided in three segments distributed in the central $1076 \mathrm{~m}$ of the cross-section). The plane strain calculations are based on the assumptions of small strains and linear elasticity. No vertical locking was imposed along the lateral boundaries of the domain although its size rules out any significant boundary disturbances. This domain is comprised of stacked horizontal layers whose Young's moduli increase with depth. To obtain a realistic estimate of the vertical profile of elasticity modulus (Fig. 4), we used the $10 \mathrm{~km}$ deep vertical seismic profile of shear wave velocity $V_{\mathrm{s}}$ calculated by Jongmans and Camelbeeck [18] for the Stavelot massif (NE Ardenne) from seismograms recording quarry blasts. Using $V_{\mathrm{s}}$, we can determine the dynamic modulus of elasticity $E_{\mathrm{d}}$ by using the following relationship:

$E_{\mathrm{d}}=2 \rho \cdot(1+v) \cdot V_{\mathrm{s}}^{2}$

where we take $\rho$, the density of upper crustal rocks, $2700 \mathrm{~kg} / \mathrm{m}^{3}$ and $v$, the Poisson's coefficient, 0.25 .

To convert $E_{\mathrm{d}}$ into $E_{\mathrm{s}}$, the static modulus of elasticity, we use a coefficient of reduction $C_{\mathrm{r}}$ taking the 'quality' of the massif (mainly related to its degree of fracturation) into account. In the absence of field determination of this quality fac- 


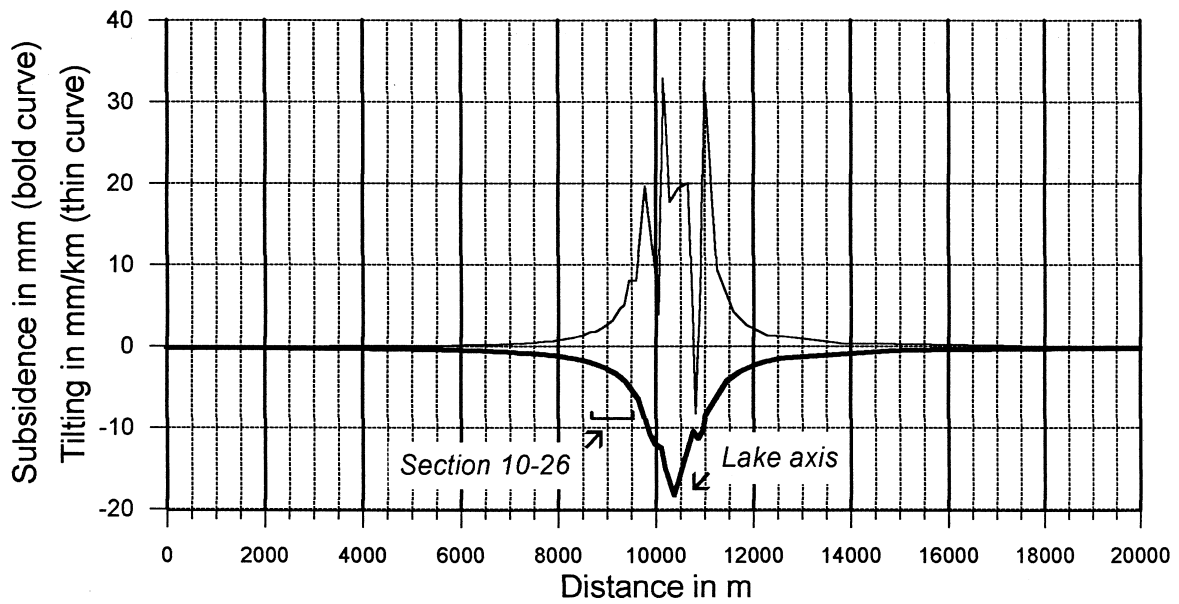

Fig. 5. Modeling of ground subsidence (bold line) and tilting (thin line) in the Gileppe area for an applied pressure of $123.2 \mathrm{kPa}$ centered in $X=10400$ (intersection of the lake long axis with the modeled cross-section). The location of the leveled Bethane section is also shown.

tor, we estimated it by means of an empirical relationship linking the coefficient of reduction to the wavelength of the shear waves [19]. We thus obtained a value of 0.16 for $C_{\mathrm{r}}$ in the fractured bedrock near the surface. This value was taken for the upper $3 \mathrm{~km}$ of the model, down to the main interface corresponding to the Eifel thrust (i.e. the northern Variscan front in NW Europe). Below the thrust fault, we assumed a linear increase of $C_{\mathrm{r}}$ with depth, due to the progressive closure of the fractures with increasing confining pressure. Finally, we took $C_{\mathrm{r}}=1$ for the bottom $5 \mathrm{~km}$ of the domain. Of course, the obtained $E_{\mathrm{s}}$ values can only be considered as rough estimates.

We calculated the vertical ground displacement for a pressure of $123.2 \mathrm{kPa}$, corresponding to the maximum lake level variation of $12.56 \mathrm{~m}$ recorded

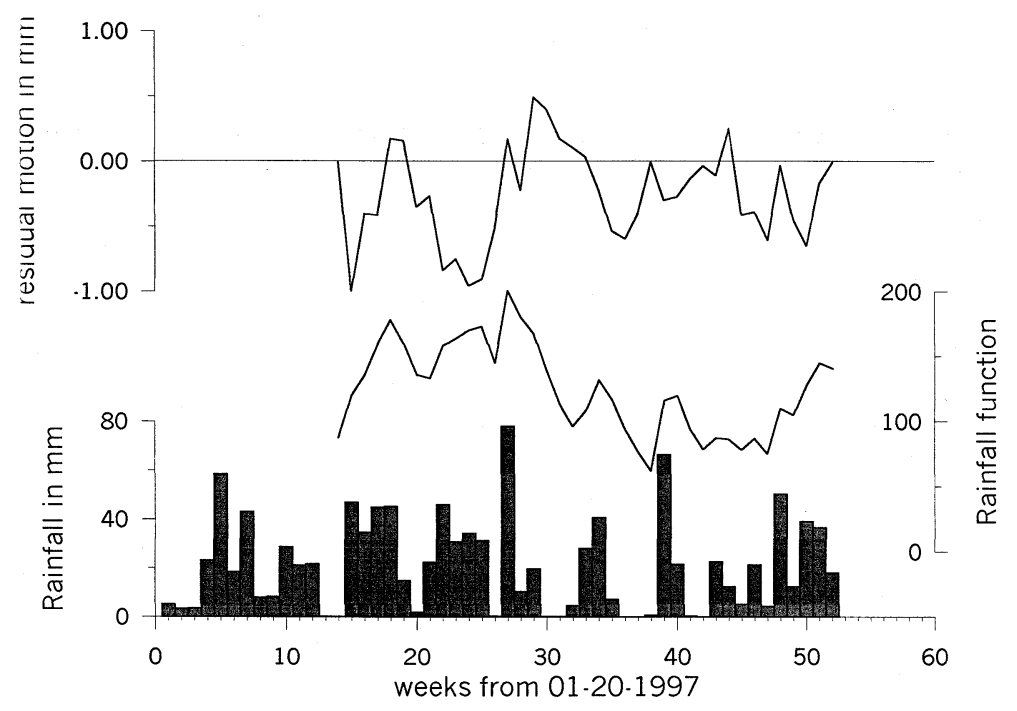

Fig. 6. Upper curve: Residual (observed modeled) motion of the Béthane section after removal of the influence of waterload variations in the Gileppe Lake. Lower curve: Rainfall function calculated for a time constant $\tau=6$ (weeks). 
in the 1993-1998 time period (during which the yearly levelings of the Gileppe Lake network were performed). The calculated curve given in Fig. 5 shows a maximum subsidence of $18 \mathrm{~mm}$ straight below the lake axis. This value is only a rough estimate of the true amount of subsidence since $3 \mathrm{D}$ effects are not accounted for. Namely, the calculated subsidence strongly depends on the orientation of the modeled cross-section with respect to the lake, which determines the intercepted lake length where the pressure is applied. Nevertheless, it looks like a realistic figure because the crosssection runs almost at right angle to the axis of this narrow lake, thus reducing the problem to that of bending under a line load. More interestingly, the ground lowering rapidly damps down when going away from the reservoir axis. At a distance of $2.5 \mathrm{~km}$, it becomes negligible $(<1$ $\mathrm{mm})$.

For the Béthane section whose endmarks are respectively 0.8 and $1.7 \mathrm{~km}$ away from the lake axis, the same pressure of $123.2 \mathrm{kPa}$ causes an average tilt of about $3.5 \mu$ rads toward the lake, i.e. a differential vertical movement of $3.2 \mathrm{~mm}$ between both endmarks. However, the maximum variation of the lake level during the 1997-1998 campaign of weekly levelings did not exceed 10.55 $\mathrm{m}$, corresponding to a pressure of $103.5 \mathrm{kPa}$. This yields a calculated differential motion of $2.7 \mathrm{~mm}$ between benchmarks 10 and 26 .

\section{Discussion}

\subsection{The influence of waterload variations}

This calculated motion of $2.7 \mathrm{~mm}$ is clearly of the same order of magnitude as the measured 3.45 $\mathrm{mm}$. Moreover, except for a few transient excursions discussed below, the temporal evolution of measured height change variations of the Béthane section closely follows that inferred from modeling (Fig. 6). The Pearson's coefficient of correlation between measured tilt at Béthane and load variations within the lake is 0.92 for the 1997 1998 data set, and the regression equation is al-

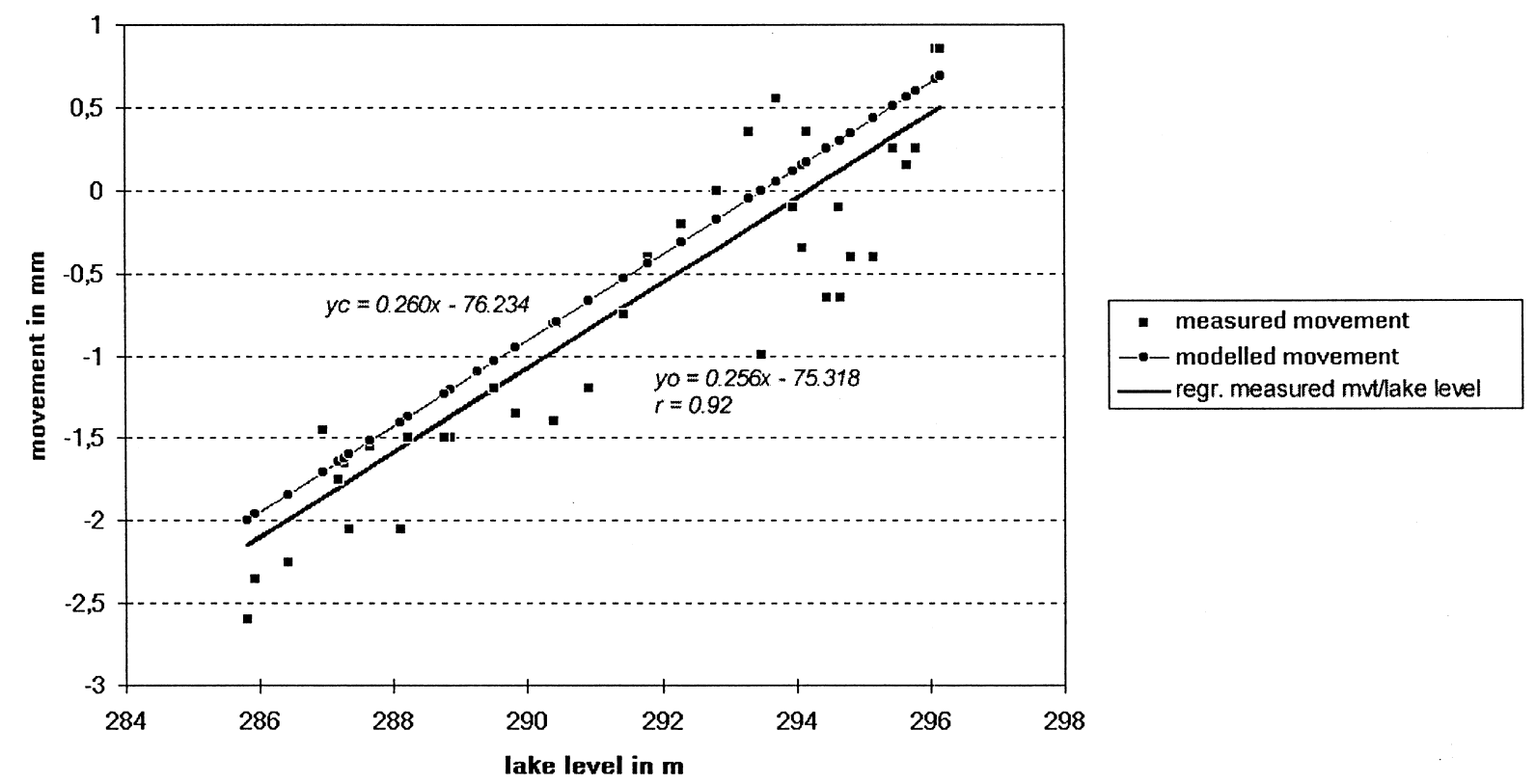

Fig. 7. Regression of the observed vertical ground motion on the lake level variations. The equation of the linear regression $\left(y_{\mathrm{o}}\right)$ is given in the right part of the diagram with the Pearson's coefficient of correlation. The equation of the modeled influence of waterload variations $\left(y_{\mathrm{c}}\right)$ is given in the left part of the diagram. 
most identical with the calculated relationship between both parameters (Fig. 7). This undoubtedly confirms that in this particular place vertical ground movements are primarily caused by the varying water level in the Gileppe reservoir.

An internal report of EDF France dealing with the elastic deformation of the ground caused by the filling of the Vouglans reservoir $\left(590 \times 10^{6} \mathrm{~m}^{3}\right)$ on the Ain River (SE France) in 1968 yields comparable results by a different approach taking into account the total load (Duffaut, written communication). It suggests a maximum subsidence at the gravity center of the loaded area amounting to $9.3 \mathrm{~cm}$ for a mean $\sigma_{\mathrm{z}}$ of about $750 \mathrm{kPa}$. Similar results have also been obtained from the computation of the elastic ground response to the $M_{2}$ (principal lunar semi-diurnal) component of sea tide loading in the Bay of Fundy, where a tide amplitude of about $14 \mathrm{~m}(\sim 137 \mathrm{kPa})$ would be responsible for a maximum vertical displacement of $24 \mathrm{~mm}$ [17].

The reliability of our calculations is further confirmed by the ground movements measured after filling of several very large reservoirs. Located on the Zambezi River (Zambia-Zimbabwe), the Kariba Lake $\left(150 \times 10^{9} \mathrm{~m}^{3}\right)$ is one of the world's largest artificial reservoirs. Subsidence of up to $13 \mathrm{~cm}$ has been measured in the vicinity of the deepest part of the lake (125 m deep, corresponding to a local pressure of 1.2 $\mathrm{MPa}$ ) [20]. High precision levelings carried out from 1935 to 1950 after the Lake Mead (Nevada, AZ, USA) was filled showed a ground depression of about $18 \mathrm{~cm}$ near the gravity center of the $200 \mathrm{~m}$ deep reservoir [21]. In both these cases, the measured vertical displacement is about $30 \%$ smaller than the computed motion (even a little more for the elastic depression in the Lake Mead area, where the above mentioned value of subsidence has been obtained with a $15 \mathrm{yr}$ time lag with respect to the lake filling and thus includes a viscous component of the deformation). This slight discrepancy is simply due to the location of the leveled points, which cannot actually coincide with the drowned places of maximum loading.

With regard to the area of influence, the comparison, based on yearly leveling data for the 1993-1997 period, of measured and computed
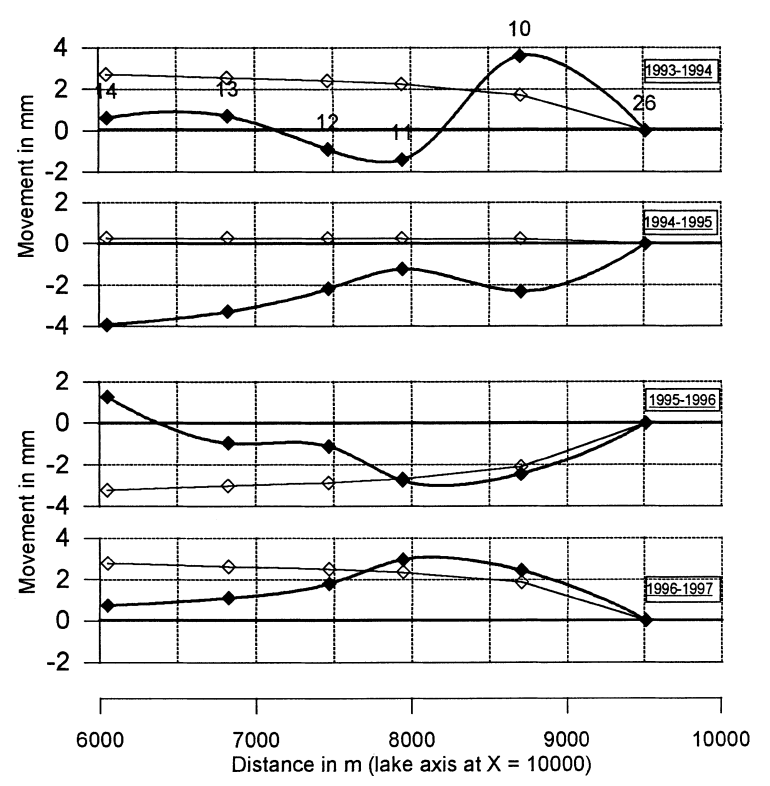

Fig. 8. Yearly record of vertical ground movements to the north of the Gileppe Lake from 1993 to 1997, showing the spatially limited influence of waterload variations within the lake. Bold lines display the measured movements and thin lines the modeled displacements. Benchmark numbers are indicated along the upper curve.

vertical displacements in the network part more distant from the Gileppe Lake unequivocally demonstrates that the effect of such small waterload variations indeed is limited to a $2-3 \mathrm{~km}$ wide peripheral area (Fig. 8). For example, the oscillatory tilting observed since 1994 between benchmarks 11 and 14 (immediately to the NNW of the Béthane section) is completely independent of this influence, as well as all other geodetically significant displacements recorded elsewhere in the Gileppe network [6].

\subsection{The passive influence of faults}

Although the significance of motion of individual nails inside the section may be questioned, comprehensive information on the evolution of the nail positions in time and space corroborates that given by the behavior of the intermediate bedrock marks to suggest that the section is not uniformly tilted but rather is comprised of two zones of markedly different movement separated 


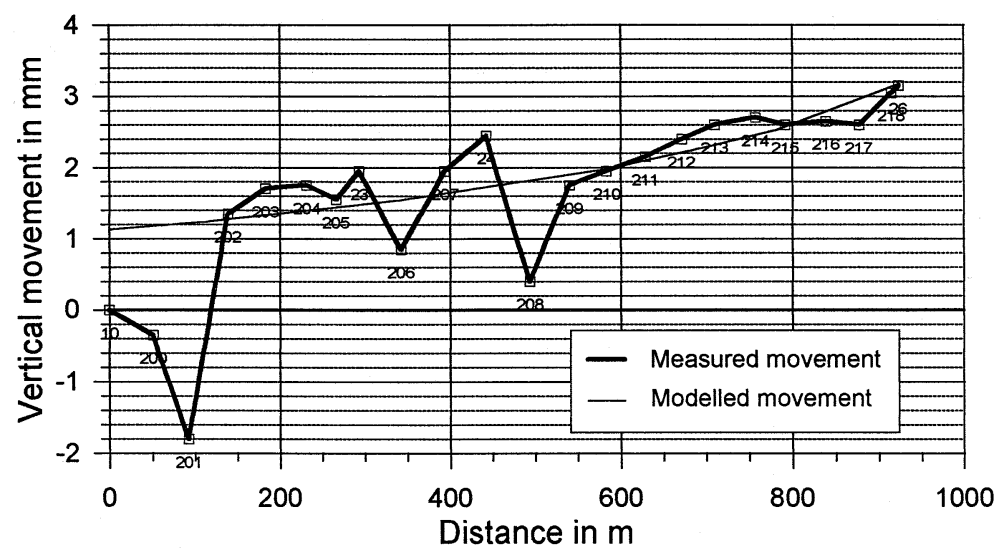

Fig. 9. Spatial coincidence of measured and modeled movements along the Béthane section for the August 4, 1997-December 8, 1997 period. Benchmarks anchored in the Paleozoic bedrock are located in 23, 24 and 211.

by a sharp cutoff. Considering for instance the time interval between August, 4 and December 8, 1997 during which no other important displacement interferes with the ground response to waterload variations, it appears that the spatial coincidence between measured and calculated nail positions is excellent, except for the three most remote marks of the section (benchmark 10+2 nails) (Fig. 9). This abrupt discontinuity may be interpreted as resulting from the presence of an NNW-striking fault crossing the leveling route between nails 201 and 202. Indeed, recent activity of that Variscan fault following the Gileppe valley is evidenced by terrace deformations in the nearby Vesdre Valley [22]. However, the differential motion on both walls of the fault is here determined solely by the ground response to the varying lake level, such passive fault motion only highlighting that the upper part of the fault is not locked.

The presence of this fault (that we shall call the Béthane fault) could contribute to explain why the measured maximum amplitude of $3.45 \mathrm{~mm}$ of vertical movement for the Béthane section exceeds by $25 \%$ the calculated value of $2.7 \mathrm{~mm}$. Indeed, the stress transfer is partly hampered by the fault, thus increasing the amount of waterloaddependent motion on the lake side of the fault and diminishing it on the other side. Since the Béthane section straddles the fault, the differential movement it records is therefore enhanced.

\subsection{The superimposition of possible tectonic motion}

As already stated, only few significant deviations from the time response curve of ground motion to waterload are observed along the Béthane section. The main one appears in June and July 1997 (Fig. 6, weeks 18-29). It corresponds to a 1.1 $\mathrm{mm}$ high transient motion which developed in 5 weeks and was more than recovered $(1.5 \mathrm{~mm})$ in a period of similar length immediately after. Spatially, this movement is located between nails 201 and 202, again taking place along the Béthane fault. Furthermore, some minor tilt excursions (Fig. 6, week 15) are also linked to sudden small displacements on this fault. Besides these tilt excursions within the Béthane section, other sections of the Gileppe network also showed some nonreversible fault displacements (Fig. 8: $2.7 \mathrm{~mm}$ between benchmarks 11 and 10 in the 1993-1994 interleveling period).

Despite the particular location of these shortterm residual up-and-down movements on fault traces, their possible relation to atmospheric or especially hydrological causes needs further consideration. Indeed, many such ground deformations which had been previously ascribed to a tectonic source were later demonstrated to result from the influence of rainfall and subsequent soil moisture and water table changes [23-25]. However, the sensitivity of different geodetic instru- 
ments, in most cases tiltmeters and strainmeters, to rainfall influence is strongly linked to their baselength [10]. In this respect, leveling is far less sensitive to ground response to rainfall than tilt measurements, whose results cannot therefore be transposed to the leveling scale. Nevertheless, we must check whether the seasonal variations of the residual vertical motions observed at Béthane correlate with the rainfall distribution.

Rainfall data (Fig. 6) are recorded at the Gileppe Dam, $1 \mathrm{~km}$ apart from the Béthane section. To take into account the assumption that a single rain causes an impulse-like ground deformation followed by exponential recovery corresponding to the subsequent progressive drying out of the soil, we calculated a cumulative function from the convolution of rainfall with an exponential function [26]:

$f_{i}=\sum_{k=i-p}^{i} r_{k} \cdot \mathrm{e}^{\left(t_{k}-t_{i}\right) / \tau}$

where $r_{k}$ is the amount of rain for the $k$ th week, $\tau$, the time constant, has been taken successively equal to 4 and 6 weeks and $p=12$, corresponding to the model order. After removal of the waterload-dependent component of the observed vertical ground displacement, we regressed the residual motion onto this rainfall function (Fig. 6). In order to account for possible phase shift, we also searched for lagged correlations but in spite of considering ground response delays of up to 10 weeks, we found no significant relationship linking both variables.

As mentioned above, the absence of any kind of water table data clearly prevents definitive conclusions to be drawn regarding the role of its variations. However, several lines of evidence strongly suggest a limited, most probably insignificant influence on ground movements of the Béthane section. Firstly, the similar geomorphic setting of both section endmarks at barely $1 \mathrm{~km}$ from each other makes it improbable that differential changes in groundwater level be large enough to determine a measurable tilt of the ground surface. From the observations of Evans and Wyatt [10], we note for example that, despite significant induced changes in hydraulic gradient, daily purging of several tens of meters of water from a borehole in low-porosity granodiorites (including an hydrothermally altered zone at $94 \mathrm{~m}$ depth) caused downward ground displacement of only $0.01-0.02 \mathrm{~mm}$ in the close vicinity of the hole. Secondly, water table variations are generally not independent from rainfall [12], and we may make an argument of the absence of correlation between ground motion and the calculated rainfall function for further discarding the influence of groundwater. Furthermore, the vertical movement of the additional benchmarks anchored in the outcropping Paleozoic basement within the Béthane section remarkably fits that of the endmarks 10 and 26, thus highlighting that possible groundwater fluctuation in the alluvial deposits on which the endmark-bearing buildings rest does not influence the latter's stability.

Compared to the hydrologically caused ground deformation, the thermoelastic effects [27] and the influence of atmospheric pressure changes are much smaller and can be neglected here $[9,28]$. The absence of correlation with any considered atmospheric or hydrological factor as well as the particular location of the residual movements displayed in Fig. 6 thus suggest that they could be related to deeper-seated causes, of direct or indirect tectonic origin. With regard to this possible origin, we have to discuss two characteristics of the displacement: amplitude and reversibility. Considering firstly the amplitude, the millimetric size of the residual fault displacements (and their short-term episodicity as well) makes them very similar to the so-called 'fault-creep' events characterizing some segments of major strike-slip faults $[29,30]$. However, the tilt excursions described here for the Béthane section are rapidly more or less completely recovered. This is further confirmed by the recovering of most geodetically inferred fault displacements in NE Ardenne [6]. Although Demoulin and Collignon [6] interpreted them as typical of the 'tectonic noise' which would characterize the zones of maximum strain along the limbs of crustal buckles in areas of neotectonic uplift, no known tectonic faulting process can as yet provide a satisfying mechanical explanation of these reversible motions. Thus, despite frequent descriptions of similar geodetically in- 
ferred up-and-down ground movements [2], their tectonic origin remains questionable.

\section{Conclusion}

Weekly levelings of a $1 \mathrm{~km}$ long section located close to a small reservoir of $25 \times 10^{6} \mathrm{~m}^{3}$ in $\mathrm{NE}$ Ardenne and a 2D finite element modeling of the influence of waterload variations in the reservoir on ground displacement have shown that this influence is restricted to a $2-3 \mathrm{~km}$ wide peripheral area where it causes seasonal tilt of up to 3-4 $\mu$ rads. A localized spatial discrepancy between measured and modeled movement is explained by the presence of a fault. While its Quaternary activity is demonstrated by river terrace deformation, the influence of this fault is here passive. However, after removal of the waterload-dependent component of motion, there remain oscillating residual displacements of $1-1.5 \mathrm{~mm}$ amplitude with a typical 'period' of about 2 months. Most of these movements also take place on the fault and we thus addressed the question of their near-surface vs. tectonic origin. The observed residual displacements appeared to be unrelated to all hydrological and atmospheric parameters we considered. Though highly improbable, only a possible role of water table variations could not be definitely ruled out. However, no alternative tectonic mechanism is able to satisfactorily explain the occurrence of such short-term sense reversals of motion, whose true nature remains enigmatic.

\section{Acknowledgements}

we are greatly indebted to A. Pissart, J.L. Génicot (benefiting from a 'prime' contract of the Walloon Region), R. Ancion and T. Dewez for field assistance. We also acknowledge useful discussion with J.P. Radu, A. Pissart and D. Jongmans. Constructive comments of reviewer $\mathrm{M}$. Kasser also led to considerable improvement of the paper.[AC]

\section{References}

[1] H. Kooi, P. Johnston, K. Lambeck, C. Smither, R. Molendijk, Geological causes of recent $(\sim 100 \mathrm{yr})$ vertical land movement in the Netherlands, Tectonophysics 299 (1998) 297-316.

[2] P. Sychev, V. Zacharov, V. Semakin, On the origin of recent and modern vertical movements in the island systems of northeastern Asia, Tectonophysics 122 (1986) 283-305.

[3] J. Fourniguet, Géodynamique actuelle dans le nord et le nord-est de la France, Mém. BRGM 127, Orléans, 1987, $160 \mathrm{pp}$.

[4] A. Demoulin, A. Pissart, K. Zippelt, Neotectonic activity in and around the southwestern Rhenish shield (West Germany): indications of a levelling comparison, Tectonophysics 249 (1995) 203-216.

[5] A. Demoulin, T. Launoy, K. Zippelt, Recent crustal movements in the southern Black Forest (western Germany), Geol. Rundsch. 87 (1998) 43-52.

[6] A. Demoulin, A. Collignon, The nature of the recent vertical ground movements inferred from high precision leveling data in an intraplate setting: NE Ardenne, Belgium, J. Geophys. Res. (2000), in press.

[7] R. Reilinger, M. Bevis, G. Jurkowski, Tilt from releveling: an overview of the US data base, Tectonophysics 107 (1984) 315-330.

[8] F. Wyatt, Displacement of surface monuments: vertical motion, J. Geophys. Res. 94 (1989) 1655-1664.

[9] R. Edge, T. Baker, G. Jeffries, Borehole tilt measurements: aperiodic crustal tilt in an aseismic area, Tectonophysics 71 (1981) 97-109.

[10] K. Evans, F. Wyatt, Water table effects on the measurement of earth strain, Tectonophysics 108 (1984) 323-337.

[11] H. Kümpel, J. Peters, D. Bower, Nontidal tilt and water table variations in a seismically active region in Quebec, Canada, Tectonophysics 152 (1988) 253-265.

[12] C. Braitenberg, Estimating the hydrologic induced signal in geodetic measurements with predictive filtering methods, Geophys. Res. Lett. 26 (1999) 775-778.

[13] A. Demoulin, N. Lenôtre, J. Moxhet, A. Pissart, Les régions néotectoniques de la Belgique définies par la comparaison de nivellements, Ann. Soc. Géol. Belg. 115 (1992) 99-111.

[14] Institut Géographique militaire (IGM), Deuxième nivellement général. Répertoire des définitions et des altitudes des repères, Bruxelles, 1949, 148 pp.

[15] R. Stein, Discrimination of tectonic displacement from slope-dependent errors in geodetic leveling from southern California, 1953-1979, in: Earthquake Prediction. An International Review, Maurice Ewing Ser. Vol. 4, AGU, Washington, 1981, pp. 441-456.

[16] R. Stein, C. Whalen, S. Holdahl, W. Strange, W. Thatcher, Saugus-Palmdale, California, field test for refraction error in historical leveling surveys, J. Geophys. Res. 91 (1986) 9031-9044. 
[17] P. Vanicek, E. Krakiwsky, Geodesy. The Concepts, 2nd Edn., Elsevier, Amsterdam, 1986, 697 pp.

[18] D. Jongmans, T. Camelbeeck, Structure superficielle de la croûte en Ardenne belge obtenue à partir des enregistrements de tirs de carrière: méthodologie et premiers résultats, Ann. Soc. Géol. Belg. 116 (1994) 119-127.

[19] A. Monjoie, C. Schröder, Auscultation des massifs rocheux par sismique réfraction et propriétés géodynamiques des terrains, in: Proceedings III International Congress IAEG, Section IV 2, 1978, pp. 29-36.

[20] D.I. Gough, W.I. Gough, Stress and deflection in the lithosphere near Lake Kariba, Geophys. J. 21 (1970) 65-78 (Part I), 79-101 (Part II).

[21] J.M. Raphael, Crustal disturbances in the Lake Mead area, Eng. Monograph Vol. 21, Bureau of reclamation (Technical Information Branch), Denver Federal Center, Denver.

[22] A. Demoulin, Quaternary tectonics in the northern Ardennes, Belgium, Tectonophysics 163 (1989) 315-321.

[23] Y. Tanaka, I. Naito, Gradual crustal movements with some periodicity and the related phenomena, J. Geod. Soc. Jpn. 22 (1976) 311-313.
[24] K. Kasahara, Migration of crustal deformation, Tectonophysics 52 (1979) 329-341.

[25] M. Kasahara, R. Shichi, Y. Okada, On the cause of longperiod crustal movement, Tectonophysics 97 (1983) 327 336.

[26] J. Langbein, R. Burford, L. Slater, Variations in fault slip and strain accumulation at Parkfield, California: initial results using two-color geodimeter measurements, 1984 1988, J. Geophys. Res. 95 (1990) 2533-2552.

[27] J. Harrison, K. Herbst, Thermoelastic strain and tilts revisited, Geophys. Res. Lett. 4 (1977) 535-537.

[28] G. Dal Moro, M. Zadro, Subsurface deformations induced by rainfall and atmospheric pressure: tilt/strain measurements in the NE-Italy seismic area, Earth Planet. Sci. Lett. 164 (1998) 193-203.

[29] K. Steinbrugge, E. Zacher, D. Tocher, C. Whitten, C. Claire, Creep on the San Andreas fault, Bull. Seismol. Soc. Am. 50 (1960) 389-415.

[30] C. Scholz, The Mechanics of Earthquakes and Faulting, Cambridge University Press, Cambridge, 1990, 439 pp. 